\title{
The difference in the locomotor activity of horses during solitary and paired release
}

\author{
Anna Stachurska', Monika Różańska-Boczula² and Elżbieta Wnuk-Pawlak? \\ 1 Department of Horse Breeding and Use, University of Life Sciences in Lublin, Akademicka 13, 20-950 Lublin, Poland \\ 2 Department of Applied Mathematics and Computer Science, University of Life Sciences in Lublin, Głęboka 28, 20-950 Lublin, Poland
}

\begin{abstract}
Summary: The objective of the study was to determine the difference in the locomotor activity of horses that are maintained with conspecifics and released into a paddock with a companion or alone. Three horses out of eleven adult Hucul geldings in the facility which were housed in pairs in box-stalls and released outdoor together were randomly included in the study. Each horse studied stayed in the box-stall with another horse which was not included in the study. Horses were released into the experimental paddock for $1 \mathrm{~h}$ daily over 12 days for the investigation. One solitary horse followed by one pair of horses were observed every day. The locomotor activity was quantified as the number of steps in walking, trotting or cantering and the number of changes in gait from a slower gait to a faster gait and conversely, from a faster gait to a slower gait. The influence of the treatment effect was estimated with the non-parametric Wilcoxon signed-rank test. The non-parametric Friedman test was used to estimate the day effect. The results show that the mean number of forelimb steps in trot and canter and changes in the gait were higher during paired release than in solitary release. The tendency for a higher number of steps in walk during paired release was insignificant. The Friedman test did not reveal any significant differences between the successive days. The lower locomotor activity in horses turned out alone compared to solitary release indicates that the companion provokes the other horse's locomotion, even when the horses are maintained with conspecifics for the whole day. Considering the benefits of movement, paired turnout may be one of the factors which provide appropriate welfare for horses. This finding has implications for optimising the turnout circumstances. When voluntary exercise is desired, the horse should not be released alone. The issue warrants further investigation in horses maintained without conspecific company.
\end{abstract}

Keywords: horse, paddock, locomotor activity, release, welfare

Citation: Stachurska A., Różańska-Boczula M., Wnuk-Pawlak E. (2021) The difference in the locomotor activity of horses during solitary and paired release. Pferdeheilkunde 37, 50-55; DOI 10.21836/PEM20210107

Correspondence: Prof. Anna Stachurska, Department of Horse Breeding and Use, Faculty of Animal Sciences and Bioeconomy, University of Life Sciences in Lublin, Akademicka 13 str., 20-950 Lublin, Poland; anna.stachurska@up.lublin.pl

Submitted: July 29, 2020 | Accepted: September 22, 2020

\section{Introduction}

Horses are commonly released outdoor every day with the aim of providing the welfare of domestic horses and adapting modern management to natural circumstances as much as possible. Minimal stay times for horses in outdoor enclosures are legislated in some countries (Glauser et al. 2015). Staying in the paddock or pasture allows for free movement, which covers physiological demands and maintains the horse's fitness and muscle tone. Regular access to paddocks also lowers the psychosomatic response of the horse to stress (Janczarek et al. 2016).

Exercise is a requirement for good welfare (Cooper and Albentosa 2005). The early exercise of foals has a positive effect on their development, modifying organ systems and metabolic pathways, for example, developing neuromuscular control and co-ordination, improving muscle mass and bone mineral density, and increasing the resistance to obesity. By contrast, insufficient exercise can cause diseases of the musculoskeletal and respiratory systems. In the case of induced exercise, it is difficult to plan an optimal workload for a horse (Rogers et al.
$2012 a, b)$. When the exercise is free in an enclosure, a horse will prefer to not overload itself.

Releasing horses into a paddock imitates freedom and, thus, enables psychical relaxation, reducing the risk of behavioural disorders, such as stereotypies (Cooper et al. 2000). Horses are gregarious animals that live in harem bands in the wild. They need intervisibility, and auditory and olfactory contact with other conspecifics (Werhahn et al. 2012b). The horses are deprived of social contact in the single stalls that are commonly used. When the horse is turned out with a companion, the need for contact can be fulfilled. However, some horses are housed in groups or together with a conspecific in the box-stall, to prevent, inter alia, solitary confinement (Pierard et al. 2018, Visser et al., 2014).

Horses are not usually released into paddocks for long. This results partly from a system of management in a stable and labour costs. Some competition horses are turned out alone due to the risk of injury or are deprived of free exercise due to the false belief that horses' willingness to perform is negatively influenced by voluntary exercise (Hartmann et al. 2009, Wer- 
hahn et al. 2011, 2012b). However, forced exercise reduces the general activity in the paddocks (Jørgensen and Bøe 2007). Racehorses never have free exercise, although their access to paddocks was found to be beneficial (Janczarek ef al. 2016.

Providing food for domestic horses eliminates their need to look for it and, therefore, domestic horses do not forage most of the time like free-ranging horses do (Hampson et al. 2010a). Lee et al. (2011) raised the question of how long domestic horses prefer to stay out of the stable. Preference tests showed that warm blooded horses chose to spend $42-278 \mathrm{~min}$ in the paddock within a group and 17 min when they were turned out alone. Perhaps such a short time spent in the paddock was associated with the fact that during evolution, horses optimised their ability to interact with and adapt to their domestic environment (Ohl and Van der Staay 2012). By contrast, weanling foals in loose housing spent $51.4 \%$ of their time in the open paddock and their locomotor behaviours consisted of $5 \%$ of observations (Autio and Heiskanen 2005). Horses given a 2-h turnout a week showed increased activity compared to those released for $12 \mathrm{~h}$ weekly (Chaya et al. 2006). Open stables and particularly active stables with functional elements located in different places increase the activity and social contact of the horses (Rose-Meierhöfer et al. 2010). However, housing horses alone is more widespread (Pierard et al. 2018).

In the study by Werhahn et al. (2012a), two horses released together onto pasture, after $1 \mathrm{~h}$ of eating, spent more time in social interactions and less time walking and trotting than horses turned out alone. Hence, social interactions seem to be more important for the horses than voluntary movement. It is an interesting question whether activity is considerably elevated when horses are not alone during turnout. Observations frequently show solitary horses standing still in the paddock, not profiting from social interactions or from free exercise. Humans usually prefer the horses to move in the paddock and not stand quietly. The objective of the study was to determine the difference in the locomotor activity of horses that are maintained with conspecifics and are released into a paddock with a companion or alone.

\section{Materials and Methods}

Horses and husbandry

There were eleven adult Hucul geldings used for leisure riding for an hour daily in the facility. They were housed in pairs in box-stalls measuring $4.5 \times 4.5 \mathrm{~m}$ and were turned out into a paddock together (social herd), for $6 \mathrm{~h}$ daily in autumn and winter, irrespective of weather conditions. The $100 \times 100$ $\mathrm{m}$ paddock was equipped with a shelter and three feeders, where meadow hay was provided. Hucul horses are a primitive breed that has a strong herd instinct which is characteristic of feral and free-ranging horses (Stachurska et al. 2006).

Three horses out of the herd were randomly included in the study: five (A), seven (B) and nine (C) years old. The horses studied did not stand out from the herd with any specific be- haviours or elevated excitability and did not exhibit individual preferences towards each other. Each horse studied stayed in the box-stall with another horse which was not included in the experiment.

\section{Paddock used for the experiment}

The paddock used for the study had a sand-covered surface and was situated $100 \mathrm{~m}$ from the stable in an open, unshielded area, away from any roads, noise or other stressors. It measured $20 \times 40 \mathrm{~m}$ and was fenced with an electric wire. Water and food were not available in it and no green growth around the paddock was present. The horses studied were familiar with this paddock and the electric fence. They could not see the herd turned out in the big paddock lying on the other side of the stable from this situation. Faeces were collected from the experimental paddock after each hour of the investigation.

\section{Experimental procedure}

The study was performed in February over 12 successive days. Horses were released into the experimental paddock for $1 \mathrm{~h}$ daily for the investigation. They had their left forelimb strapped with a bandage of a bright colour to facilitate the observations. One solitary horse followed by one pair of horses were observed every day. The next day, a different single horse was released alone, whereas the single one from the previous day was examined together with a companion. Thus, each horse was examined four times alone and eight times with a companion (Table 1). The single horse was turned out at 8:00-9:00 a.m. and the pair of horses at 9:15-10:15 a.m.. Except for this procedure, we did not interfere with the daily facility regime. The herd remained in the big paddock behind the stable from 8:00 a.m. $-2: 00$ p.m. After the experimental hour, the horses studied were released into the herd, which stayed in the big paddock. They were used for riding lessons in the afternoon, as before.

\section{Data}

The locomotor activity was quantified as (1) the number of steps in walking, trotting or cantering and (2) the number of changes in gait from a slower gait to a faster gait and conversely, from a faster gait to a slower gait (between walk and trot, walk and canter, and trot and canter). Other gaits were not observed and left canter or right canter were not distinguished (Robilliard et al. 2007). More than three steps with-

\begin{tabular}{|c|c|c|}
\hline \multicolumn{3}{|c|}{$\begin{array}{l}\text { Table } 1 \quad \text { Outline of the first three days of the experiment (the } \\
\text { schedule was conducted four times) | Überblick über die erster } \\
\text { drei Tage des Experiments (der Zeitplan wurde viermal durchgeführt) }\end{array}$} \\
\hline Experimental day & $\begin{array}{l}\text { Solitary horse } \\
\text { 8:00-9:00 a.m. }\end{array}$ & $\begin{array}{l}\text { Paired horses } \\
\text { 9:15-10:15 a.m. }\end{array}$ \\
\hline 1. & $A$ & $B, C$ \\
\hline 2. & B & $A, C$ \\
\hline 3. & C & $A, B$ \\
\hline
\end{tabular}


out interruption were recorded as a gait. Any situations while standing, when a horse raised and moved its leg, for example, to change position, were not taken into account.

The observations were carried out by the same one or two people every day, according to whether one or two horses were released. The observers sat still, close to the paddock, and were visible to the horses. The turnouts were continuously recorded on video for the later analysis of moments when the observation was not clear.

\section{Weather conditions}

During the experiment, the air temperature in the hours of turnouts varied between -4 and $+1^{\circ} \mathrm{C}$. It was lightly snowing, raining, drizzling or there was freezing rain. Only two days had no precipitation, however, these days were cloudy. The wind speed ranged from 5.5 to $17.7 \mathrm{~km} / \mathrm{h}$.

\section{Statistical analysis}

The statistical evaluation of the data was carried out using Statistica 13.0 software. The data from successive days were added up. Most of the data could not be transformed into Gaussian distribution, hence, the influence of the treatment effect (release condition: solitary/paired) was estimated with the non-parametric Wilcoxon signed-rank test. The non-parametric Friedman test was used to estimate the day effect. Inter-rater reliability provided by coders ensuring consistency in ratings across subjects (horses) was assessed using two-way average-measures intra-class correlation. Calculations were made with the R programme (Hallgren 2012).

\section{Results}

The locomotor activity in horses during $1 \mathrm{~h}$ of solitary and paired release into paddock was compared in terms of the number of steps in particular gaits and number of changes in gaits. The factor of the release condition was statistically significant for all locomotor activity parameters $(\alpha=0.05)$,

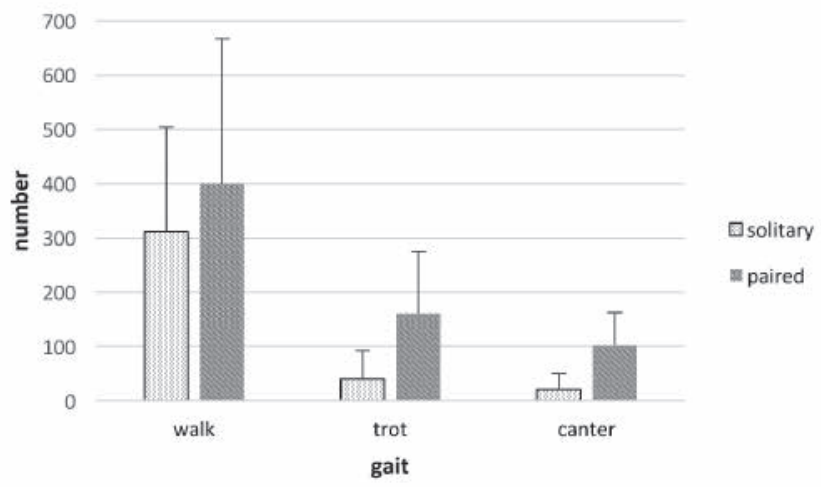

Fig. 1 Mean number of steps of the left forelimb in various gaits in the condition of solitary or paired release (whiskers show standard deviation) | Mittlere Anzahl der Schritte des linken Vorderbeines in verschiedenen Gangarten bei einzelner oder paarweiser Haltung auf dem Paddock (Whisker zeigen Standardabweichung) except for the number of steps in walk ( $p>0.05)$. The tendency of a higher number of steps in walk during paired release was insignificant. The mean number of forelimb steps in trot and canter and the mean number of all types of changes in the gait were higher during paired release than in solitary release (Figure 1 and 2). The Friedman test did not reveal any significant differences between the successive days. A satisfactory inter-rater reliability level was found for each feature analysed: Intra-class correlation values ranged from 0.55 to 0.70 .

\section{Discussion}

Satisfying the Five Freedoms, inter alia, to express normal behaviour by providing sufficient space, proper facilities and company of a conspecific, leads to good welfare (McCulloch 2012). However, many negative experiences cannot be entirely eliminated by delivering the Freedoms but can be only reduced to tolerable levels. The positive effects of the Freedoms are mainly increased opportunities to behave in ways the animals find rewarding (Mellor 2016). Legislative procedures provide a minimum standard of care and management for animal welfare (Rogers et al. 2012a). According to developing knowledge regarding the horses' needs, the legislation can be improved and adjusted, which, in turn, shows the practical use of conducting scientific research in this discipline.

We focused on the horses' locomotor activity in the present study. Other behaviours were not considered as they were a different issue. Moreover, social interactions were not possible to observe in a solitary condition. Only three horses were studied, however, the measurements were repeated many times under similar circumstances. The low number of similar animals ensured that some factors, such as the horse's breed or sex, which could bias the results were eliminated. The horses were observed in the first hour of turnout. One hour is a usual practice for releasing horses into paddocks in the winter, hence the study was based on typical circumstances. The weather conditions were similar during the experimental days. The lack of significant differences

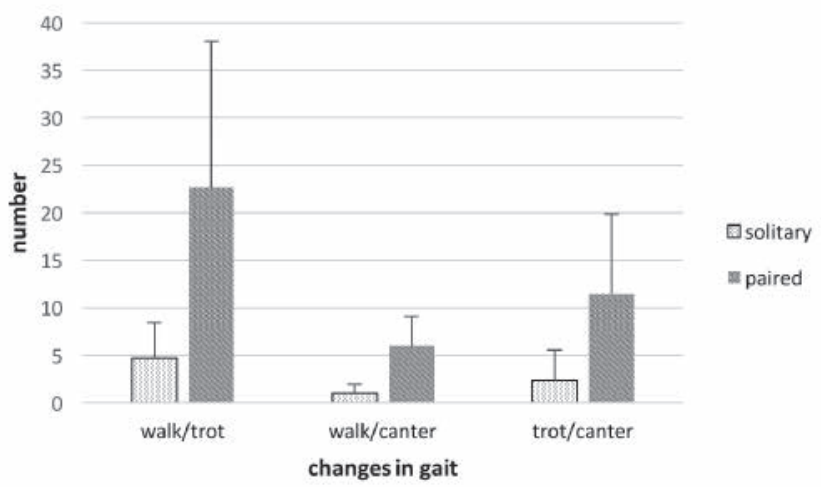

Fig. 2 Mean number of changes in gait in both directions (towards a faster or slower gait) in the condition of solitary or paired release (whiskers show standard deviation) | Mittlere Anzahl der Gangwechsel in beide Richtungen (in Richtung einer schnelleren oder langsameren Gangart) bei einzelner oder paarweiser Haltung auf dem Paddock (Whisker zeigen Standardabweichung) 
between the data from successive days of the study shows that the weather did not influence the results considerably. The behaviour of foals in a paddock studied by Autio and Heiskanen (2005) did not change much as the air temperature dropped from 0 to $-20^{\circ} \mathrm{C}$, hence, the temperature in the present study could not bias the results. The size of the paddock in our study conformed to, for example, Danish recommendations of a minimum of $800 \mathrm{~m}^{2}$ and, thus, it agreed with sizes commonly used (Jørgensen and Bøe 2007). We were not using devices such as pedometers attached to the neck collar or front legs, which are particularly practical for taking readings from large numbers of horses for many hours or days (Bachmann et al. 2014, Warren-Smith and McGreevy 2010), or GPS tracking collars, which measure the distance travelled (Hampson et al. 2010b). We focused on differences in the locomotor activity when the horse is isolated from the group of conspecifics and from the stable companion under solitary or paired conditions. Taking single horses out of a group released into a paddock often occurs in riding facilities when a horse is needed for a riding lesson. A similar situation occurs during shows when a horse is taken out of the schooling area.

According to many authors, feral and free-ranging horses as well as stabled horses released into a paddock devote a short part of their time budget to locomotion (Boyd and Bandi 2002, Chaya et al. 2006, Duncan 1980). They are agitated only in the first few moments after the time spent in the stable. They then mainly walk, whereas trot and especially canter are rare. Our results of low locomotor activity observed for horses maintained under stable-paddock conditions fully agree with those findings. The main and sometimes exclusive gait was walk. Trot occurred rarely and canter was seen even more rarely. Since the experimental paddock was barren and peaceful, the locomotor activity was not associated with foraging or trying to escape from a startle stimulus. We cannot exclude possible frustration due to a lack of roughage and shelter. However, the horses were studied for only $1 \mathrm{~h}$ a day. The locomotor activity seems to result from the desire to exercise, explore the area or play with a companion. According to many authors (Duncan 1980, Houpt et al. 2001, Werhahn et al. 2011 ), the intensity of horses' free locomotion might also be influenced by other factors, such as the sex and age of the horses, the exercise induced daily or longer stall confinement, however, these factors were also eliminated from this investigation.

The horses studied before and during the experiment were subject to excellent social conditions since they were maintained with a conspecific in box-stalls and released into the paddock in a herd. They were alone for only the experimental hours over 12 days, hence, their needs for social interaction seemed to be fulfilled. It was discovered that even when the effect of psychical needs is limited, the influence of the solitary or paired release factor on the locomotor activity is prominent. It is interesting how horses suffering from solitary confinement in the stable would react during solitary or paired turnout, which needs further investigation. Our results show that when a horse not deprived of conspecific company is turned out alone, its locomotor activity is significantly lower than when it is together with a companion. The numbers of steps in trot and canter as well as the number of changes in the gait are a few times lower under solitary release circumstances. It appears that the companion provokes the other horse's locomotion. The fact that locomotor intensity is lower in horses released alone corresponds with the finding by Lee et al. (2011) about horses' preference for a longer duration in grouped than in a solitary turnout.

\section{Conclusion}

According to our results, horses that are maintained with conspecifics express lower locomotor activity during solitary turnout compared to paired release. Considering the benefits of movement, paired turnout may be one of the factors which provide appropriate welfare for horses. This finding has implications for optimising the turnout circumstances. The lower locomotor activity during solitary turnout suggests that the horse should not be released alone particularly when voluntary exercise is desired. This issue warrants further investigation in horses maintained without conspecific company.

\section{Conflict of interest}

The authors report no conflicts of interest. The authors alone are responsible for the content and writing of this article.

\section{Animal welfare statement}

Animal care and experimental procedure were in accordance with the Directive 2010/63/EU of the European Parliament and of the Council on the protection of animals used for scientific purposes and were approved by the Local Ethics Review Committee for Animal Experiments (no 27/2016).

\section{References}

Autio E., Heiskanen M. L. (2005) Foal behaviour in a loose housing/ paddock environment during winter. Appl. Anim. Behav. Sci. 91, 277-288; DOI org/10.1016/i.applanim.2004.10.012

Bachmann M., Wensch-Dorendorf M., Hoffmann G., Steinhöfel I., Bothendorf S., Kemper N. (2014) Pedometers as supervision tools for mares in the prepartal period. Appl. Anim. Behav. Sci. 151, 51-60; DOl org/10.1016/i.applanim.2013.11.014

Boyd L., Bandi N. (2002) Reintroduction of takhi, Equus ferus przewalskii, to Hustai National Park, Mongolia: time budget and synchrony of activity pre- and post-release. Appl. Anim. Behav. Sci. 78, 87-102; DOI 10.1016/S0168-1591(02)00088-6

Chaya L., Cowan E., McGuire B. (2006) A note on the relationship between time spent in turnout and behaviour during turnout in horses (Equus caballus). Appl. Anim. Behav. Sci. 98, 155-160; DOI 10.1016/i.applanim.2005.08.020

Cooper J. J., Albentosa M. J. (2005) Equine behavior and welfare. In: McDonnel, S.M., Mills, D. S. (Eds.), The domestic horse: the evolution, development and management of its behaviour. Cambridge University Press, Cambridge UK, pp. 228-238

Cooper J. J., McDonald L., Mills D. S. (2000) The effect of increasing visual horizons on stereotypic weaving: implications for the social housing of stabled horses. Appl. Anim. Behav. Sci. 69, 67-83; DOI 10.1016/S0168-1591(00)00115-5

Duncan P. (1980) Time budgets of Camargue horses. II. Time budgets of adult horses and weaned sub-adults. Behaviour 72, 2649; DOI 10.1163/156853980X00023 
Glauser A., Burger D., Van Dorland H. A., Gygax L., Bachman I., Howald M., Bruckmaier, R. M. (2015) No increased stress response in horses on small and electrically fenced paddocks. Appl. Anim. Behav. Sci. 167, 27-34; DOI org/10.1016/i.applanim.2015.03.008

Hallgren K. A. (2012) Computing Inter-Rater Reliability for Observational Data: An Overview and Tutorial. Tutor Quant Methods Psychol. 8, 23-34; DOI 10.20982/tqmp.08.1.p023

Hampson B. A., de Laat M. A., Mills P. C., Pollitt C. C. (2010a) Distances travelled by feral horses in 'outback' Australia. Equine Vet. J. 42, 582-586; DOI 10.1111/j.2042-3306.2010.00203.x

Hampson B. A., Morton J. M., Mills P. C., Trotter M. G., Lamb D. W., Pollit C. C. (2010b) Monitoring distances travelled by horses using GPS tracking collars. Aust. Vet. J. 88, 176-181; DOI 10.1111/j.1751-0813.2010.00564.x

Hartmann E., Winther Ch. J., Keeling L. J. (2009) Social interactions of unfamiliar horses during paired encounters: Effect of pre-exposure on aggression level an so risk of injury. Appl. Anim. Behav. Sci. 121, 214-221; DOI 10.1016/j.applanim.2009.10.004

Houpt K., Houpt T. R., Johnson J. L., Erb H. N., Yeson S. C. (2001) The effect of exercise deprivation on the behaviour and physiology of straight stall confined pregnant mares. Anim. Welfare 10, 257-267

Janczarek I., Kędzierski W., Stachurska A., Wilk I. (2016) Can releasing racehorses to paddocks be beneficial? Heart rate analysis - preliminary study. Ann. Anim. Sci. 16, 87-97; DOI 10.1515/ aoas-2015-0049

Jørgensen G. H. M., Bøe K. E. (2007) A note on the effect of daily exercise and paddock size on the behaviour of domestic horses (Equus caballus). Appl. Anim. Behav. Sci. 107, 166-173; DOI 10.1016/i.applanim.2006.09.025

Lee J., Floyd T., Erbs H., Houpt K. (2011) Preference and demand for exercise in stabled horses. Appl. Anim. Behav. Sci. 130, 91-100; DOI 10.1016/i.applanim.2011.01.001

McCulloch S. P. (2012) A critique of FAWC's Five Freedoms as a framework for the analysis of animal welfare. Journal of Agricultural and Environmental Ethics 26, 5; DOI 10.1007/s10806-012-9434-7

Mellor D. J. (2016) Updating animal welfare thinking: moving beyond the "Five Freedoms" towards "a life worth living". Animals 6, 3, 21; DOI 10.3390/ani6030021
Ohl F., Van der Staay F. J. (2012) Animal welfare: at the interface between science and society. Vet. J. 192, 13-19; DOI 10.1016/i. tvjl.201 1.05.019

Pierard M., McGreevy P., Geers R. (2018) Effect of density and relative aggressiveness on agonistic and affiliative interactions in a newly formed group of horses. J. Vet. Behav. 29, 61-69; DOI 10.1016/i.jveb.2018.03.008

Rogers C. W., Bolwell C. F., Gee E. K. (2012a) Proactive Management of the Equine Athlete. Animals 2, 640-655; DOI 10.3390/ ani2040640

Rogers C. W., Bolwell Ch. F., Tanner J. C., Van Weeren P. R. (2012b) Early exercise in the horse. J. Vet. Behav. 7, 375-379, DOI 10.1016/i.jveb.2012.01.003

Rose-Meierhöfer S., Klaer S., Ammon Ch., Brunsch R., Hoffman G. (2010) Activity behaviour of horses housed in different open barn systems. J. Equine Vet. Sci. 30, 624-634; DOI 10.1016/i. jevs.2010.10.005

Stachurska A., Pięta M., Jackowski M., Tarnawa-Wójciga A. (2006) Difficulty of obstacles at Hucul Path - events for Hucul horses. Electronic Journal of Polish Agricultural Universities, Animal Husbandry. http://www.eipau.media. pl/volume9/issue4/art-09. html

Warren-Smith A., McGreevy P. (2010) The use of pedometers to estimate motor laterality in grazing horses. J. Vet. Behav. 5, 117-179; DOI 10.1016/i.jveb.2009.12.023

Werhahn H., Hessel E. F., Schulze H., Van den Weghe H. F. A. (2011) Temporary turnout for free exercise in groups: Effects on the behaviour of competition horses housed in single stalls. J. Equine Vet. Sci. 31, 417-425; DOI 10.1016/i.jevs.2011.01.006

Werhahn H., Hessel E. F., Van den Weghe H. F. A. (2012a) Competition horses housed in single stalls (I): Behaviour and activity patterns during free exercise according to its configuration. J. Equine Vet. Sci. 32, 45-52; DOI 10.1016/i.jevs.2011.06.007

Werhahn H., Hessel E. F., Van den Weghe H. F. A. (2012b) Competition horses housed in single stalls (II): Effects of free exercise on the behaviour in the stable, the behaviour during training, and the degree of stress. J. Equine Vet. Sci. 32, 22-31; DOI 10.1016/i. jevs.2011.06.009 